\title{
Sex-Gender Differences in Irritable Bowel Syndrome
}

\author{
Young Sun Kim ${ }^{1}$ and Nayoung Kim ${ }^{2,3 *}$ \\ ${ }^{I}$ Department of Internal Medicine, Healthcare Research Institute, Seoul National University Hospital Healthcare System Gangnam Center, Seoul, \\ Korea; ${ }^{2}$ Seoul National University Bundang Hospital, Seongnam, Gyeonggi-do, Korea; ${ }^{3}$ Department of Internal Medicine and Liver Research \\ Institute, Seoul National University College of Medicine, Seoul, Korea
}

Because of the sex-gender differences that are shown in a diversity of physiological and psychological factors, it can be speculated that the clinical presentation of symptoms as well as treatment strategies in women and men with irritable bowel syndrome (IBS) may differ. Studies have revealed that IBS is more common in women than men. As for the IBS subtype, IBS with constipation is significantly more prevalent among women than men. Sex hormones and gender differences may play important roles in the pathophysiology of IBS. However, its pathophysiologic mechanisms still remain largely unknown, and therapeutic implications are limited. Moreover, women IBS patients have been reported to feel more fatigue, depression, anxiety, and lower quality of life than men IBS patients. Furthermore, there has been evidence of differences in the appropriate treatment efficacy to IBS in men and women, although relatively few men are enrolled in most relevant clinical trials. A more sex-gender-oriented approach in the medical care setting could improve understanding of heterogeneous patients suffering from IBS. An individualized and multicomponent approach including sex and gender issues might help improve the treatment of IBS.

(J Neurogastroenterol Motil 2018;24:544-558)

Key Words

Gender; Hormones; Irritable bowel syndrome; Sex

\section{Introduction}

Irritable bowel syndrome (IBS) is one of the most common functional gastrointestinal disorders (FGID), defined by abdominal pain and abnormal bowel habits with no detectable organic disease. ${ }^{1}$ The pathophysiology of IBS is multifactorial with sex-gender factors seeming to play important roles, as previous studies have suggested there to be sex and gender-associated differences in the prevalence and subtypes of IBS, as well as the effectiveness of treat- ment for IBS. Interestingly, most FGIDs in general show female predominance. $^{2}$

Sex means biological distinctions characterizing males and females, whereas gender reflects sex-related social roles with which an individual identifies, and that presumably reflect learned femininity or masculinity. ${ }^{3}$ Sex or gender-specific medicine is a rising medical field in which relevant differences between males and females are recognized and actively utilized in both diagnosis and treatment. Gender is assumed to be a crucial factor in the pathogenesis, disease progression, and even prognosis of various diseases. ${ }^{4-6}$

Received: May 10, 2018 Revised: August 8, 2018 Accepted: August 24, 2018

() This is an Open Access article distributed under the terms of the Creative Commons Attribution Non-Commercial License (http://creativecommons. org/licenses/by-nc/4.0) which permits unrestricted non-commercial use, distribution, and reproduction in any medium, provided the original work is properly cited.

*Correspondence: Nayoung Kim, MD, PhD Department of Internal Medicine, Seoul National University Bundang Hospital, 82, Gumi-ro 173 beon-gil, Bundang-gu, Seongnam, Gyeonggi-do 13620, Korea

Tel: +82-31-787-7008, Fax: +82-31-787-4051, E-mail: nayoungkim49@empas.com 
However, there have been only a few reports of gender differences in FGIDs, mostly on prevalence, ${ }^{7}$ specified gastrointestinal (GI) symptoms, ${ }^{8}$ or quality of life (QoL) ${ }^{9}$ seen in IBS. Even though IBS is more common in women, the underlying mechanism by which women exhibit an increased vulnerability to IBS remains largely unknown, and therapeutic treatments are also limited. ${ }^{2}$

From this background, our review article focuses on sex and gender differences with regard to the prevalence, pathophysiology, clinical presentations, and treatment of IBS based on valuable studies in the literature.

\section{Methodology}

First, we set up a search strategy for PubMed with combined $\mathrm{MeSH}$ terms and free text terms in order to build a broad discovery net for articles on IBS and these terms; sex, gender, epidemiology or prevalence, pathophysiology, sex hormone, symptoms, and treatment. These searches were performed targeting only full literatures written in English.

All searches were completed by 20th April, 2018 (Fig. 1). Every retrieved abstract was reviewed in order to investigate whether the results included sex or gender differences, as well as whether original data revealed abstracts satisfying these criteria were included in the next level of review regarding study design, subjects, and clinical variables. Next, we reviewed full text articles that met our

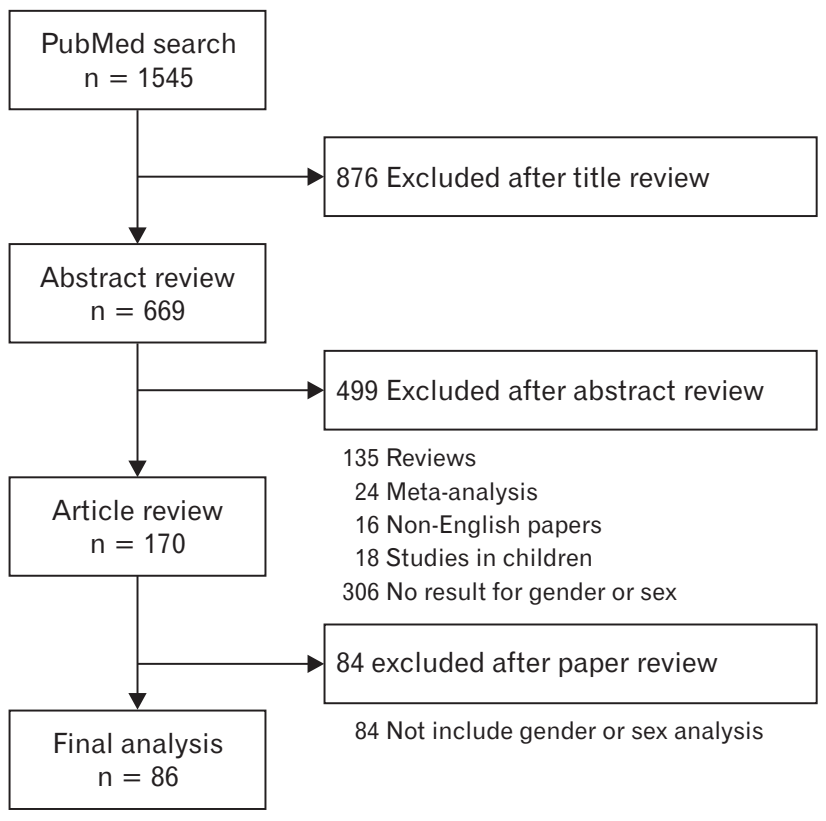

Figure 1. Flow chart documenting the results of the search strategy. inclusion criteria, based on the contents of the abstract.

We then retrieved related articles and reviewed their reference lists. Finally, we found a total of 170 suitable articles, of which 84 articles were excluded because they were irrelevant to the specific questions being asked. Finally, 86 original articles were included in our review.

\section{Prevalence}

IBS has been reported be a more common disease in women, with a female-to-male ratio of 2-2.5:1 in terms of those who seek medical care. ${ }^{10,11}$

However, the prevalence of IBS could differ depending on the clinical setting in terms of race, geography, community base, or whether a study was performed in a primary or tertiary hospital setting, as well as the enrolled number of men or women, definition criteria for IBS used (Rome vs Manning), or method of data collection (Postal questionnaire, telephone interview, self-administered questionnaire, or interview-administered questionnaire). ${ }^{12-18}$ Moreover, differences in access to health care and cultural factors, such as help-seeking behavior, may contribute to prevalence differences as well. ${ }^{6,13,15-18}$

A recent systemic review for 83 studies conducted in 41 countries including 288103 participants (55.0\% women) by a Rome foundation working team showed significant variation in pooled regional prevalence; the mean prevalence among individual countries ranged from $1.1 \%$ in France and Iran to $35.5 \%$ in Mexico. ${ }^{19}$ Even among studies conducted within the same country, there were significant differences in prevalence. ${ }^{19}$ Considering sex difference in pooled prevalence, women showed higher prevalence than men ( $10.2 \%$ vs $8.8 \%$ ), and the prevalences were also higher in women than men in each region separately. ${ }^{19}$ However, an Indian study showed a higher prevalence among men than women because men more often consult doctors than women do in India. ${ }^{19,20}$

Another systemic review and meta-analysis for 55 studies containing 162543 subjects showed that the pooled prevalence of IBS was higher in women than in men $(14.0 \%$ vs $8.9 \%$; OR, $1.67 ; 95 \%$ CI, 1.53-1.82). ${ }^{15}$

The prevalence of IBS in women may also vary according to geographic region. ${ }^{13}$ In Asia the distribution is fairly equal between men and women, but in the United States, Israel, and Canada, the disorder is twice as prevalent in women. The differences in the OR of IBS in women compared to those in men according to geographical location were statistically significant (Cochran Q, 82.89; $P<$ $0.001) .{ }^{13}$ These results may be caused by the various differences 
between Asian and Western patients with IBS, including a hygiene hypothesis model, differences in intestinal microbiota and diet, or cultural differences in healthcare-seeking behavior. ${ }^{21}$

However, until now, it has been unclear whether the gender difference in the prevalence of IBS is actually associated with physiologic differences or differing medical care-seeking behaviors. Medical care-seeking behaviors can be affected by several factors, such as disease severity, accessibility, psychological stress, and sociocultural circumstances. ${ }^{22,23}$

In general, women have been shown to have higher risk for post-infection IBS. A recent systematic review and meta-analysis showed that women, particularly those with severe enteritis, are at increased risk for developing IBS. Female sex was associated with a 2.2 times higher OR of developing postinfectious IBS (OR, 2.19; 95\% CI, 1.57-3.07). ${ }^{24}$

The sex-related difference in the prevalence of IBS appears around puberty and increases during the early adult years. ${ }^{25} \mathrm{In}$ women, IBS occurs most commonly from the late teens to the midforties. As age continues to increase thereafter, the incidence of IBS in women decreases and approaches the rate in men around the age of 70 years old and above. ${ }^{25}$ In contrast, the prevalence of IBS among men remains constant from 20 to 70 years of age. ${ }^{25,26}$ It has been suggested that sex hormones play a potential role in these gender differences regarding the epidemiology, pathophysiology, and treatment outcome in IBS patients, as well as the association between IBS symptoms and sex hormonal status (menstrual cycle phases, pregnancy, menopause, and hormonal replacement therapy). ${ }^{25,27}$

\section{Clinical Symptoms}

IBS is mainly classified according to the predominant bowel habit, such as IBS with constipation (IBS-C), IBS with diarrhea (IBS-D), IBS with mixed bowel habits (IBS-M), and unclassified IBS. $^{28}$

There are gender differences in IBS symptoms; specifically IBS-C is predominant in women whereas IBS-D is predominant in men. ${ }^{12,16}$ In a systematic review and meta-analysis performed for 22 studies regarding gender differences in IBS symptoms, women were found to be more likely to report abdominal pain and constipation-related symptoms than men (all $P<0.05$ ) ${ }^{16}$ In contrast, men with IBS were more likely to report diarrhea-related symptoms than women with IBS. ${ }^{16}$ The pooled prevalence of IBS-C in women with IBS was $40 \%$, compared to $21 \%$ in men with IBS (OR, 2.38; $95 \% \mathrm{CI}, 1.45-3.92)$. The pooled prevalence of IBS-D in women with IBS was $31 \%$ compared to $50 \%$ in men (OR, $0.45 ; 95 \% \mathrm{CI}$,
0.32-0.65). The prevalence of IBS-M in women with IBS was $25.8 \%$ compared to $25.0 \%$ in men (OR, 1.07; $95 \% \mathrm{CI}, 0.84-1.38) .{ }^{16}$

In addition, the prevalences of chronic pain disorders that often overlap with IBS, such as fibromyalgia, chronic fatigue syndrome, chronic pelvic pain, and migraine headache, are higher in women with IBS, suggesting an association between their symptoms and hormonal statuses. ${ }^{25,27,29-32}$ Women report more frequent and severe IBS symptoms during menstruation such as loose stools, bloating, and worsening of abdominal pain, increases that are likely related to changes in the menstrual cycle. ${ }^{25}$

In a population-based postal study performed in Iceland, women with dysmenorrhea were revealed to experience IBS symptoms more frequently than those without dysmenorrhea. ${ }^{33}$ In addition, menopause seems to be associated with the exacerbation of IBS symptoms. That is, women reported more severe abdominal pain following menopause than before menopause. ${ }^{32}$ However, another study demonstrated that there was no significant difference $(P>$ $0.05)$ in IBS severity score system (IBS-SSS) between pre- and postmenopausal women. ${ }^{34}$ However, there are several limitations in the qualities, methods, and numbers of studies evaluating the effect of menstrual cycle, hormone supplementation, and menopausal status on IBS symptoms. For example, most of these studies depended on symptom recall. ${ }^{12}$ A study that evaluated the effect of menstrual cycle phase using ovulation kits demonstrated that the aggravation of IBS symptoms during the late luteal and early menses phases was coincident with decreased estrogen and progesterone levels. ${ }^{35}$

Considering the effect of hormone replacement therapy (HRT) on IBS symptoms, Ruigomez et $\mathrm{al}^{36}$ demonstrated that women undergoing HRT are at an increased risk of developing IBS than women who do not. However, a different study indicated that the prevalence and severity of IBS symptoms were similar among non-HRT users and HRT users. ${ }^{36}$ Gonenne et $\mathrm{al}^{37}$ showed that postmenopausal healthy women who had taken estradiol or progesterone for 7 days reported more frequent loose stools and greater ease in defecation than those on placebo. Therefore, in the case of women with IBS symptoms, more attention should be paid to menstrual irregularities, menopausal status, the use of contraceptives and hormone-replacement therapy, and history of gynecological surgery. ${ }^{38}$

\section{Pathophysiology}

The contributing factors that most influence clinical manifestation and physiologic responses in men and women with IBS are hormonal factors, visceral hypersensitivity, behavioral stress 
response, changes in gut microbiome, psychological factors, and intestinal motor and sensory functions, which are closely associated with gut-brain interactions (Fig. 2). ${ }^{34,39-43}$ However, the exact mechanisms remain unclear.

\section{Hormonal Factors}

Female sex hormones have been known to be important factors modulating the susceptibility to stress, gut motility, and visceral pain perception by interacting with neuromodulator systems and the emotional system (Fig. 2). ${ }^{34}$ Estrogen and progesterone are known to inhibit smooth muscle contraction. In addition, progesterone modulates the colonic 5-hydroxytryptamine (5-HT) system, which is known to control peristalsis. Women with IBS experience constipation more often than do men with IBS, ${ }^{44}$ except during menstrual periods, when ovarian hormone levels are low. Women are also known to have slower GI transit than men. ${ }^{45}$ The colonic transit times in women are delayed when women have higher levels of ovarian hormones. ${ }^{46}$

While most studies investigating sex-related differences in IBS have focused on the concept of female susceptibility, there has not been enough research on the role of male hormones.

Androgens have been reported to protect against the development of chronic pain disorders in humans, and testosterone has shown an analgesic effect in experimental pain models. ${ }^{47}$ Differences in androgen levels, receptors, and action sites may play a role in the sex differences in both IBS and the development of chronic

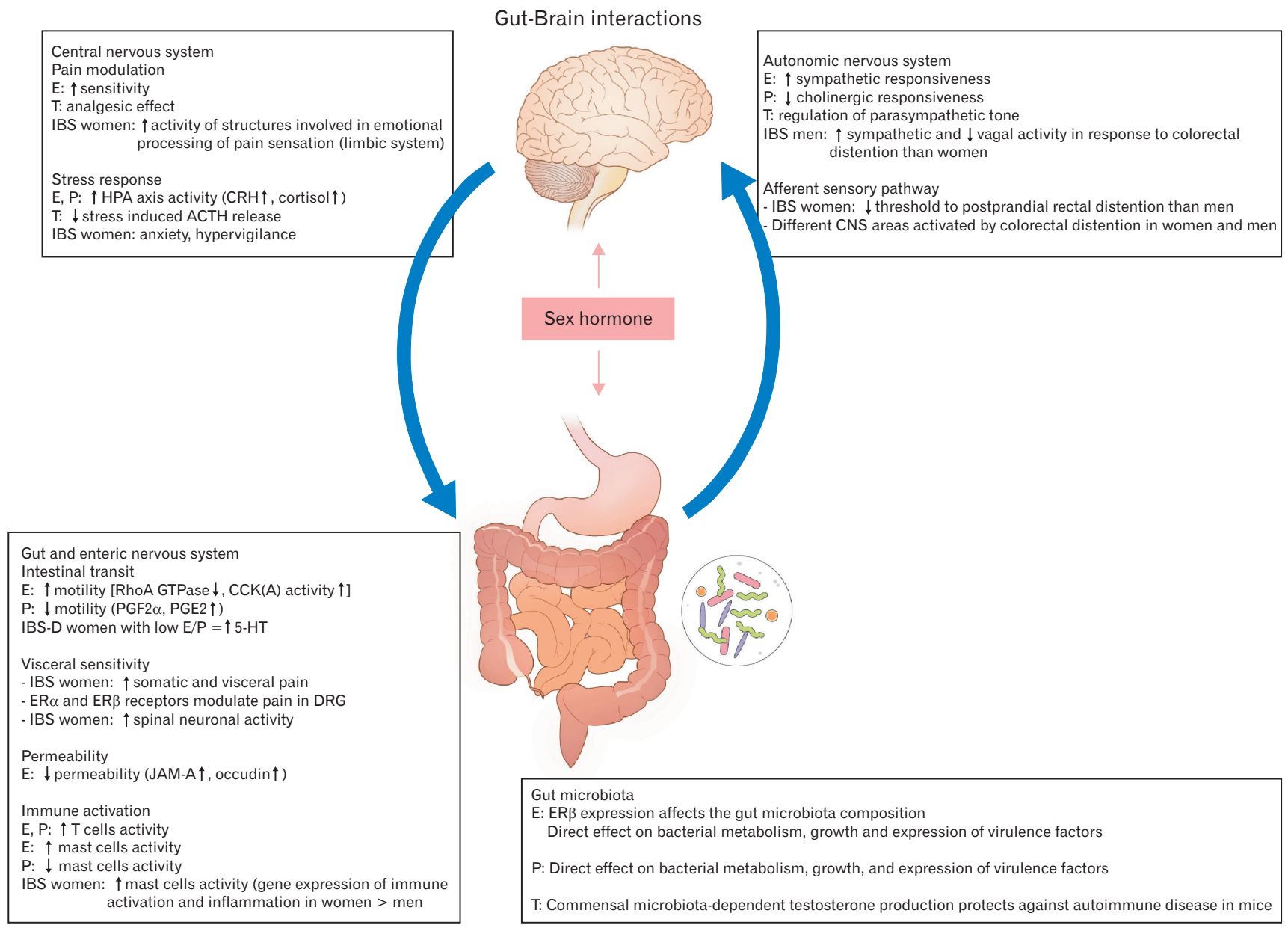

Figure 2. Brain-gut axis and sex hormones interaction in irritable bowel syndrome (IBS). Sex hormones influence peripheral and central regulatory mechanisms involved in the pathophysiology of IBS contributing to the alterations in stress response, visceral sensitivity and motility, intestinal barrier function, and immune activation of intestinal mucosa. Sex hormones also have direct effects on the gut microbiota and enteric nervous system. E, estradiol; T, testosterone; P, progesterone; CRH, corticotropin-releasing hormone; ACTH, adrenocorticotropic hormone; GTP, guanosine-5'triphosphate; CCK, cholecystokinin; PG, prostaglandin; 5-HT, 5-hydroxytryptamine; ER, estrogen receptor; DRG, dorsal root ganglion; JAM, junctional adhesion molecule. Adapted from Meleine and Matricon. ${ }^{46}$ 
pain disorders. ${ }^{48}$

A recent study showed that middle-aged men with IBS tended to have lower levels of luteinizing hormone than healthy men, and that IBS symptomatology tended to be inversely related to testosterone. ${ }^{49}$ In addition, Kim et $\mathrm{al}^{50}$ demonstrated elevated levels of sex hormone-binding globulin (SHBG) as well as testosterone, in young, male IBS patients compared to controls, suggesting that high SHBG concentration may play a role in the development of IBS.

\section{Pain Perception and Central Nervous System Activation}

There has been no conclusive data suggesting that gender influences visceral pain perception in healthy and IBS subjects. ${ }^{11}$ In general, women tend to report more severe, more frequent, and longer lasting pain than men. ${ }^{51,52}$ Studies comparing women with IBS with healthy women have shown that visceral perception is similar or increased in women with IBS compared to healthy women. ${ }^{11,53}$ Women also tended to report more abdominal pain, elevated pain perception, and discomfort during colorectal distension than men. $^{12,46,53-55}$

Estrogen is known to be a central nervous system stimulant, and androgen receptor mediation is associated with the inhibition of the central nervous system (Fig. 2), which has been suggested to lower the incidence of chronic pain disorders in men. ${ }^{52} \mathrm{~A}$ previous study has indicated that men and women respond differently to intestinal stimuli, due to morphological and functional brain differences in men and women with IBS. ${ }^{46}$ Women with IBS have also shown increased activation in areas related to the processing of emotional responses, including the amygdala and infragenual cerebral cortex, compared to men with IBS.

\section{Alteration of Cytokine and Mucosal Immune Function}

IBS has been reported to be associated with changes in cytokine profiles. ${ }^{56,57} \mathrm{~A}$ systematic review and meta-analysis showed that inflammatory cytokines in patients with IBS vary between men and women. Serum TNF- $\alpha$ levels were higher in women with IBS than in men with IBS, and interleukin (IL)-10 levels were significantly lower in men with IBS than male controls, suggesting that elevated baseline IL-10 levels in healthy men appear to serve as a protective factor against IBS. ${ }^{58}$ Another study measuring the inflammatory cytokines and oxidative stress biomarkers in men and women with IBS found that pro-inflammatory cytokines (IL-17 and TNF- $\alpha$ ) increased and anti-inflammatory cytokine (IL-10) decreased in women compared to men. ${ }^{34}$ Furthermore, women with IBS have been shown to have an increased number of colonic mucosal mast cells and decreased numbers of CD3 + and CD8 $+\mathrm{T}$ cells, ${ }^{58}$ suggesting that mucosal immune activation is sex dependent in IBS. ${ }^{2}$ However, more studies are needed in order to properly investigate whether or not stratifying IBS patients based on cytokine profile or gene polymorphisms provides new opportunities for the personalized treatment of this condition. ${ }^{59}$

\section{Intestinal Permeability}

Psychological stress affects transcellular permeability in the colon, as well as the jejunum via mast cell and eosinophil activation. ${ }^{60-63}$ Cold pain stress has been revealed to induce more potent and sustained increases in albumin, mannitol, and xylose absorption in the jejunal lumen in women with higher background stress. ${ }^{64}$

Chronic psychological stress affects epithelial tight junction protein levels in the colon. ${ }^{63} \mathrm{~A}$ recent study demonstrated that corticosterone mediated the chronic psychological stress-induced increase in intestinal permeability in rats via the decreased levels of claudin-1, occludin, and zona occludens-1 expression (Fig. 2). ${ }^{63}$ It is well known that estrogen plays an important role in maintaining the function of the GI epithelial barrier. ${ }^{64}$ Estrogens have been associated with alterations in calcium and vitamin $\mathrm{D}$ transport in the colon cell line Caco- $2,{ }^{65}$ in the increase of occludin and junctional adhesion molecule A mRNA and protein expression in the colons of female rats, Caco- 2 cells, ${ }^{66}$ and ovariectomized rats exposed to the chemical estrogen bisphenol A. ${ }^{67}$ More importantly, 2 weeks of oral treatment with a phytoestrogen-rich soy germ-fermented ingredient has been shown to prevent the stress-induced hyper-permeability and visceral hypersensitivity in female rats through estrogen receptor activation. ${ }^{68}$

However, the roles of sex hormones in the regulation of intestinal permeability have not yet been clearly understood. The effects of stress on intestinal barrier function are complex, and the roles of sex hormones are inconsistent. Further studies are needed to elucidate these roles.

\section{Gut Microbiota}

Gut microbiota play key roles in modulating the gut-brain interaction and intestinal barrier function (Fig. 2) ${ }^{69,70}$ However, the interaction of sex with gut microbiota requires further investigation. The persistent loss of microbiomes and gut-brain homeostasis could lead to lower grade inflammation and immune dysfunction, which are associated with abnormalities in secretion, changes in visceral pain recognition, and changes in motility. ${ }^{60}$ 
Sex hormones directly affect bacterial metabolism as well as the growth and expression of virulence factors through steroid nuclear receptor expression including that of $\mathrm{ER} \beta \mathrm{.}^{71} \mathrm{~A}$ recent study showed that early life microbial exposure affects the determination of sex hormone levels and modify the progression to autoimmunity in a non-obese diabetic mouse model of type 1 diabetes. ${ }^{72}$ The enhancement of testosterone production in pubescent male mice has been reported to induce changes in the gut microbiota, which consequently have protected $\mathrm{T}$ - and B-cell function development related to autoimmune diseases. ${ }^{72}$

Animal studies have found that male microbiota could be transferred to a young female and returned to the male by castration. ${ }^{73-75}$ Interestingly, a recent study has shown that male and female rat gut microbes present a different profile of short-chain fatty acids (SCFA) when metabolizing a diet supplemented in oligofructose. ${ }^{76}$ Actually, SCFAs such as acetate, propionate, and butyrate plays an important role as energy source, inflammation modulator and a part of gut motility and wound healing. ${ }^{77}$

However, there are some limitations in translating study results on the effects of sex hormones on the mucosal and the microbiotagut-brain axis into clinical practice, as most of these studies have been performed in experimental laboratory animals. ${ }^{69}$ This is mainly because long-term diet control is nearly impossible in humans. In addition, results relating to sex hormone effects on gut microbiota have been inconsistent thus far. ${ }^{60}$ More research is needed on the important roles and complex interactions of intestinal microorganisms in relation to gender differences in IBS.

\section{Quality of Life}

IBS is known to have significant impacts on the QoL of patients. ${ }^{9,78}$ However, limited data are available as to whether the impact of IBS on life differs between women and men. ${ }^{13}$ Simrén et $\mathrm{al}^{79}$ found that women with IBS reported lower QoL; higher levels of fatigue, depression, and anxiety; and less positive well-being and self-control than men with IBS. Our team has also found similar results in functional dyspepsia between women and men. ${ }^{80} \mathrm{~A}$ recent study investigating IBS-SSS, self-reported GI symptoms, and QoL in men and women found that the severities of abdominal bloating, flatulence, and rumbling were higher in women than in men, along with dissatisfaction with bowel habits. ${ }^{34}$ Women's IBS-QoL scores were significantly lower than those of men with IBS $(P<$ $0.05)$, and body image, health worries, and sexual and relationships subscores were also significantly lower in women than in men with IBS. $^{34}$
In a study performed in Korea, health-related QoL (HRQoL) was significantly lower in women with IBS than in men with IBS $(P<0.05)$. In multivariate analysis, IBS-QoL was significantly associated with sex (lower in women), overall symptom score, selfreported symptom severity, and education level. ${ }^{81}$

In an outpatient study on IBS, women were found to be more likely to avoid certain foods, jobs, domestic activities, sexual intercourse, and socializing than men. ${ }^{82}$ In addition, women IBS patients showed less decision-making authority in planning their work schedule, fewer opportunities to learn at work, and required more long-term sick leave than the control group.

It has been suggested that the impaired HRQoL of IBS patients can be explained by psychological factors. ${ }^{83-85}$ However, there have been limited studies on the gender differences related to social factors and psychological symptoms in IBS patients, ${ }^{31}$ so further studies are needed.

It is important to focus on both improving $\mathrm{QoL}$ as well as alleviating the symptoms of IBS in the treatment of IBS patients. A physician-patient relationship based on enhanced mutual understanding that helps patients make sense of IBS symptoms could improve their ability to manage their IBS in a psychologically-flexible way, consequently helping them maintain the QoL. ${ }^{86}$

\section{Gender Role in Irritable Bowel Syndrome -}

Gender differences in responsibilities and roles, such as in unpaid caring work as well as in paid work, can influence the manifestation of IBS symptoms via stress, beyond health care-seeking behavior. ${ }^{87-89}$ Within society, there are certain expectations of women or men that influence how they behave as patients and what they reveal in health care settings. Gender related cultural issues can play a role in the observed differences between female and male IBS patients. $^{87}$

Women are socialized to think that bodily functions are private and that losing control is shameful. They are also sometimes socialized to want to be thin and attractive. ${ }^{88,89}$ Toner and Akman reported that women with IBS were more worried about losing control over their bodily functions than were men with IBS, and that they were particularly concerned about diarrhea. ${ }^{22}$ Women have also reported feeling more anxious about the effects of IBS on their appearance and self-expression, including feeling clean, smelling good, not showing bloating, and being slim. ${ }^{22}$ On the other hand, men with IBS with higher scores on characteristics traditionally thought to be female, such as bring-up and emotions, showed similar attitudes to IBS women for disease. ${ }^{90} \mathrm{~A}$ significant reduction in 
male-trait scores in men with IBS compared to healthy controls has also been demonstrated. ${ }^{51}$

A study performed in an outpatient clinic using interpretative methods showed that women were affected by how IBS interrupts their relational responsibilities as partners and mothers as well as their work decrement. ${ }^{91}$ Men, on the other hand, were affected by how IBS interrupts their construction of masculinity through the 'female health concern' label attached to the disorder and the ways in which symptoms make them feel weak and unable to do anything, thereby preventing them from reliably being able to support their families. ${ }^{91}$ The better the relationship between the physician and the patient, the more effective the IBS treatment. Therefore, a more gender-oriented approach in clinical settings will increase understanding among patients suffering from IBS. ${ }^{89,91}$

\section{Treatment}

The treatment of IBS is important because symptoms can seriously degrade health-related quality of life, leading to increased use of health care and reduced work productivity. ${ }^{92,93}$ Treatments include support and reassurance, psychological interventions, dietary manipulation, alteration of the gut microbiota, and pharmacologic agents. ${ }^{94,95}$ Because of gender differences in the prevalence and pathophysiology of IBS, an individualized and multicomponent approach considering sex and gender issue is necessary for treatment. ${ }^{39,96}$

\section{Gender-related Response to Medication}

Many pharmacotherapy studies have suggested that gender related differences may exist with respect to response to medication treatment. ${ }^{97}$ For IBS-D, constipating drugs such as loperamide and atropine, diphenoxylate, or bile acid can be used. ${ }^{17}$ Thus far, there have been no reports of sex differences in the responses to these drugs. ${ }^{16,17,96}$ However, it is difficult to assess differences in responses to pharmacological treatment because most of these trials predominantly include women. ${ }^{2}$ Even though $5-\mathrm{HT}_{3}$ receptor antagonists and $5-\mathrm{HT}_{4}$ receptor agonists were reported to be more effective in treating IBS symptoms in women than in men, the exact mechanisms underlying these effects remain unclear. ${ }^{98-101}$ Alosetron, a $5-\mathrm{HT}_{3}$ receptor antagonist currently approved to treat women with severe IBS-D, has been shown to significantly improve the symptoms of women with IBS but not men with IBS ${ }^{98}$ (Table). In a follow-up study enrolling only men, IBS pain, discomfort, and stool consistency were significantly improved with alosetron treatment, but other IBS symptoms did not improve..$^{102}$ A meta-analysis of randomized, placebo-controlled trials evaluating the efficacy and tolerability of alosetron demonstrated that it was effective in both women and men with IBS. ${ }^{103}$ Another $5-\mathrm{HT}_{3}$ receptor antagonist for IBS-D, cilansetron, was found to be more effective in women that in men, although there was still an overall significant symptom improvement in men (Table). ${ }^{104}$ The $5-\mathrm{HT}_{4}$ receptor agonist tegaserod has also been reported to have greater efficacy in women with IBS. ${ }^{96,120}$ However, it is unclear whether this truly reflects genuine sex differences because studies have thus far been conducted on only a few men. Further research is needed, and these limitations should be considered when evaluating drug therapy. ${ }^{96,106,107}$ In contrast to the above treatments, the prescription of another $5-\mathrm{HT}_{3}$ receptor antagonist, ramosetron, has been limited to men with IBS$\mathrm{D}$, because its clinical efficacy has only been confirmed in men (Table). ${ }^{108,109}$ However, in a later randomized, placebo-controlled study that included female patients, a half-dose of ramosetron $(2.5 \mu \mathrm{g}$ per day) was shown to reduce the symptoms of IBS and to improve the patients' QoL. ${ }^{110,121}$ In addition, a recent meta-analysis based on 4 randomized controlled trials involving 1623 subjects showed that ramosetron was effective in relieving overall IBS symptoms in both men and women. ${ }^{122}$

IBS has also shown a familial clustering, and has been considered a complex genetic disorder, in which multiple genetic variants on several genes contribute to the development of this condition. The serotonin transporter protein is encoded by a single gene (SLC6A4) on chromosome17q11, and 44 bp insertion/deletion in serotonin-transporter-linked polymorphic region (5-HTTLPR) creates a short ( $\mathrm{S}$ ) and a long $(\mathrm{L})$ allele, which show different transcriptional efficiencies. ${ }^{123}$ Recently, we published that IBS is related to SLC6A4 5-HTTLPR polymorphism. ${ }^{124}$ That is, the L/L genotype was significantly associated with total IBS, IBS-C, and IBS alternating between diarrhea and constipation. ${ }^{124}$ In addition, IBSC patients showed reduced levels of serum serotonin compared to controls and IBS-D patients $(P=0.001){ }^{123}$ Interestingly, the 5-HT signaling differences between women and men have been suggested to be associated with the effectiveness of $5-\mathrm{HT}_{3}$ receptor antagonists. ${ }^{100}$ There were gender differences in the levels of expression of S100A (which plays a key role in the activation and sensitization of the visceral nociceptors) and SLC6A4 in the rectal mucosa of IBS-D patients and healthy controls. ${ }^{100}$ The S100A9 and SLC6A4 mRNA levels in the rectal mucosa of women with IBS-D were significantly higher than those in men. Among the healthy controls, the $S 100 \mathrm{~A} 10$ expression levels in men were higher than those in women. The S100A8 and S100A10 expression levels in women with IBS-D positively correlated with their diarrhea 
Table. Treatment Outcomes of Drug for Irritable Bowel Syndrome Depending on Sex or Gender

\begin{tabular}{|c|c|c|c|c|}
\hline Therapeutic target & Name & Dose & Mechanism of action & Effect of sex or gender \\
\hline \multirow[t]{11}{*}{$\begin{array}{r}\text { Loos stool } \\
\text { (IBS-D) }\end{array}$} & Alosetron & $0.5-1 \mathrm{mg}$ peroral bid & $\begin{array}{l}\text { 5- } \mathrm{HT}_{3} \text { receptor antago- } \\
\text { nist }\end{array}$ & $\begin{array}{l}\text { Currently available to treat women with severe IBS-D. } \\
\text { Initially demonstrated a significant improvement in } \\
\text { women but not in men. } .^{97,98} \\
\text { Later, effective in both men and women. }{ }^{101,102}\end{array}$ \\
\hline & Ondansetron & 4-8 mg peroral every $8 \mathrm{hr}$ & $\begin{array}{l}\text { 5- } \mathrm{HT}_{3} \text { receptor antago- } \\
\text { nist }\end{array}$ & Did not conduct separate analyses by sex. ${ }^{106}$ \\
\hline & Cilansetron & \multirow[t]{3}{*}{$2 \mathrm{mg}$ peroral tid } & $\begin{array}{l}\text { 5- } \mathrm{HT}_{3} \text { receptor antago- } \\
\text { nist }\end{array}$ & $\begin{array}{l}\text { Significant improvement in men compared to that in } \\
\text { women. }{ }^{103}\end{array}$ \\
\hline & \multirow[t]{2}{*}{ Tegaserod } & & 5- $-\mathrm{HT}_{4}$ receptor agonist & Greater efficacy in women. ${ }^{103}$ \\
\hline & & & & $\begin{array}{l}\text { Withdrawn from US market due to cardiovascular } \\
\text { side effects. }{ }^{100}\end{array}$ \\
\hline & \multirow[t]{2}{*}{ Ramosetron } & $5 \mu \mathrm{g}$ peroral daily & $5-\mathrm{HT}_{3}$ receptor antago- & Initially limited to men with IBS-D. ${ }^{107,108}$ \\
\hline & & $2.5 \mu \mathrm{g}$ peroral daily & nist & Now: a half-dose is prescribed for women. ${ }^{109,110}$ \\
\hline & $\begin{array}{l}\text { Bile acid } \\
\text { (Colesevelam) }\end{array}$ & $1.875 \mathrm{~g}$ peroral bid & $\begin{array}{l}\text { Decreased stool transit } \\
\text { times }\end{array}$ & Limited data ${ }^{16}$ \\
\hline & \multirow[t]{3}{*}{ Loperamide } & $\begin{array}{l}4 \mathrm{mg} \text { peroral } \\
\text { then } 2 \mathrm{mg} \text { with each }\end{array}$ & $\begin{array}{l}\text { Binds gut wall opioid } \\
\text { receptor }\end{array}$ & Limited data ${ }^{95}$ \\
\hline & & additional loose stool & Increases sphincter tone & \\
\hline & & Maximum $16 \mathrm{mg} /$ day & $\begin{array}{l}\text { Decreased stool fre- } \\
\text { quency }\end{array}$ & \\
\hline \multirow[t]{3}{*}{$\begin{array}{l}\text { Hard stool } \\
\text { (IBS-C) }\end{array}$} & Lubiprostone & $8 \mu \mathrm{g}$ peroral bid & $\mathrm{ClC}-2$ activator & $\begin{array}{l}\text { For IBS, approved for women } \geq 18 \mathrm{yr} \text { with IBS- } \\
\mathrm{C}^{96,104} \text { effective treatment of chronic idiopathic con- } \\
\text { stipation in both men and women. }^{96}\end{array}$ \\
\hline & Linaclotide & $290 \mu \mathrm{g}$ peroral daily & $\begin{array}{l}\text { Guanylate cyclase } \mathrm{C} \\
\text { receptor agonist }\end{array}$ & Efficacious in both men and women. ${ }^{115}$ \\
\hline & Eluxadoline & $100 \mathrm{mg}$ peroral bid & $\begin{array}{l}\mu \text { - and } \kappa \text {-opioid re- } \\
\text { ceptor agonist and } \\
\delta \text {-opioid receptor an- } \\
\text { tagonist }\end{array}$ & $\begin{array}{l}\text { Efficacious in both men and women. }{ }^{17,118} \\
\text { Contraindicated in patients with history of cholecys- } \\
\text { tectomy. }\end{array}$ \\
\hline $\begin{array}{l}\text { Altered gut } \\
\text { microbiota }\end{array}$ & Rifaximin & $\begin{array}{l}550 \text { mg peroral tid for } 14 \\
\text { day }\end{array}$ & $\begin{array}{l}\text { Presumed decrease in } \\
\text { gas-producing bacte- } \\
\text { ria }\end{array}$ & Did not conduct separate analyses by sex. ${ }^{91,105}$ \\
\hline \multirow{15}{*}{$\begin{array}{l}\text { Visceral } \\
\text { hypersensitivity }\end{array}$} & \multirow[t]{15}{*}{ Anti-depressant } & TCAs & \multirow{15}{*}{ Various } & \multirow[t]{15}{*}{ Did not conduct separate analyses by sex. ${ }^{11,111}$} \\
\hline & & Amitriptyline (10-59 mg), & & \\
\hline & & Imipramine (10-50 mg) & & \\
\hline & & Doxepin (10-59 mg), & & \\
\hline & & Nortriptyline (10-59 mg), & & \\
\hline & & Desipramine $10-200 \mathrm{mg}$ & & \\
\hline & & SSRIs & & \\
\hline & & Citalopram, $10-40 \mathrm{mg}$ & & \\
\hline & & fluoxetine, $10-40 \mathrm{mg}$ & & \\
\hline & & paroxetine, $10-40 \mathrm{mg}$ & & \\
\hline & & Escitalopram 10-40 mg & & \\
\hline & & Setaline $25-100 \mathrm{mg}$ & & \\
\hline & & SNRIs & & \\
\hline & & Duloxetine $30-90 \mathrm{mg}$ & & \\
\hline & & Venlafaxine $75-225 \mathrm{mg}$ & & \\
\hline
\end{tabular}


Table. Continued

\begin{tabular}{|c|c|c|c|c|}
\hline Therapeutic target & Name & Dose & Mechanism of action & Effect of sex or gender \\
\hline \multirow[t]{3}{*}{ Abdominal pain } & Dicyclomine & $20-40 \mathrm{mg}$ peroral qid & $\begin{array}{l}\text { Antagonizes acetyl- } \\
\text { choline at muscarinic } \\
\text { receptors, smooth } \\
\text { muscle relaxer, inhib- } \\
\text { its bradykinin, reduces } \\
\text { histamine induced } \\
\text { spasm }\end{array}$ & Limited data ${ }^{11,117}$ \\
\hline & Hyoscyamine & $\begin{array}{l}0.125-0.25 \mathrm{mg} \text { peroral every } \\
4 \mathrm{hr} \text { when necessary }\end{array}$ & & Limited data ${ }^{11,113}$ \\
\hline & $\begin{array}{l}\text { Peppermint oil } \\
\text { capsule }\end{array}$ & $0.2-0.4 \mathrm{~mL}$ tid & $\begin{array}{l}\text { Smooth muscle relaxer; } \\
\text { reduce gastric motility } \\
\text { by acting on calcium } \\
\text { channels (similar to } \\
\text { dihydropyridine cal- } \\
\text { cium antagonists) }\end{array}$ & Limited data ${ }^{11,113}$ \\
\hline \multirow[t]{3}{*}{ Bloating } & FODMAP & & $\begin{array}{l}\text { Decreases fermentable } \\
\text { gas-producing foods }\end{array}$ & Limited data $^{116,119}$ \\
\hline & Probiotics & Various & $\begin{array}{l}\text { Repopulate the gut with } \\
\text { more efficient bacteria }\end{array}$ & Limited data ${ }^{114}$ \\
\hline & Psychotherapy & & & Did not conduct separate analyses by sex..$^{11,111,112}$ \\
\hline
\end{tabular}

IBS-D, diarrhea-predominant IBS; IBS-C, constipation-predominant IBS; ClC-2, chloride channel-2; TCAs, tricyclic antidepressants; SSRIs, selective serotonin reuptake inhibitors; SNRIs, serotonin and norepinephrine reuptake inhibitors; FODMAP, fermentable oligosaccharides, disaccharides, monosaccharides, and polyols; bid, twice a day; tid, 3 times a day; qid, 4 times a day.

scores. ${ }^{100}$ These gender differences could lead to better understanding of the pathogenesis and treatment of IBS.

Lubiprostone, a chloride channel-2 activator, has only been approved for treatment in women with IBS-C, because it has been shown to be more effective for women with IBS-C than men. ${ }^{97}$ This increased efficacy is also shown in Table. However, although only a small number of men have participated in studies on lubiprostone, it has turned out to be an effective remedy for chronic idiopathic constipation in both women and men. ${ }^{115}$ This indicates that the determination of whether or not lubiprostone is truly a sex specific drug is limited, because the enrolled number of men in previous studies was low. ${ }^{97}$ Linaclotide, a guanylate cyclase $\mathrm{C}$ receptor agonist, has been shown to be effective in both women and men IBS patients with constipation and chronic idiopathic constipation. ${ }^{117,125}$ Eluxadoline, a $\mu$ - and $\kappa$-opioid receptor agonist and $\delta$-opioid receptor antagonist which has been approved as a therapeutic agent for IBS-D, ${ }^{118}$ has been associated with reduced abdominal pain and improved stool consistency in both women and men receiving 100 mg twice daily with sustained efficacy for more than 6 months in large, randomized, placebo-controlled trials (Table). ${ }^{126}$

Patients with IBS have altered intestinal microbiota compared to healthy individuals. ${ }^{105}$ Recently, rifaximin has been approved for
IBS-D. A set of double-blind, placebo-controlled trials (TARGET 1 and TARGET 2) demonstrated that patients (female 67.0\%) who had IBS without constipation that were treated with rifaximin for 2 weeks showed significant improvement in IBS symptoms, bloating, abdominal pain, and loose or watery stools. ${ }^{92}$ In a recent phase 3 study of patients (female $68.0 \%$ ) with relapsing symptoms of IBS-D, repeated rifaximin treatment showed significant relief of daily ratings of IBS symptoms, bloating, abdominal pain, and stool consistency. ${ }^{111}$ However, the above studies for rifaximin did not conduct separate analyses by gender.

A recently-updated systematic review and meta-analysis has shown that antidepressants and psychological therapies are effective treatments for IBS. ${ }^{112}$ A meta-analysis reviewing 7 randomized controlled trials with a total of 374 patients revealed that hypnotherapy significantly improved abdominal pain, at least in the shortterm. ${ }^{113}$ Hypnotherapy was also beneficial for overall GI symptoms and QoL. ${ }^{113}$ However, evidence for the long-term efficacy of hypnotherapy is lacking due to an insufficient number of studies. Moreover, most psychological and behavioral treatment trials did not conduct separate analyses by gender. ${ }^{2}$

For the treatment of IBS, modest benefits over placebo have been reported with fiber, anticholinergics, and peppermint oil. ${ }^{90}$ 
However, since the randomization or allocation concealment is not explicitly described in many studies, the selection bias is also unclear. In addition, no separate analysis of gender difference was undertaken., ${ }^{2,127}$

For other drugs commonly used to treat motility disturbance (domperidone, opioid-based constipating agents, and laxatives), there is no evidence of any gender-related differences in efficacy. ${ }^{96}$

Sex differences in pharmacokinetics have often been considered to be important determinants of the clinical effect of drug treatment. ${ }^{128,129}$ Most medications for IBS are metabolized via the cytochrome P450 (CYP) pathway, which could be affected by the female sex hormones of estrogen and progesterone. ${ }^{130}$ Women generally have less lean body mass that can affect drug clearance, different activities of CYP enzymes (40.0\% increase in CYP3A4, various reductions in CYP2D6, CYP2C19, and CYP1A2), and different drug metabolism rates with men. ${ }^{129,130}$

In addition, women have been shown to have a significantly higher risk of developing adverse drug reactions than men. ${ }^{129,131}$ However, clinically significant differences in therapeutic responses based on gender differences in pharmacokinetics seem to be uncommon. ${ }^{2,89,132}$ Further studies are warranted to further clear up those issues.

Some patients do not respond well to treatment. A recent multicenter study analyzed risk factors for poor treatment response in Japanese IBS patients. ${ }^{133}$ It found that lower mental component summary and the female sex were independent risk factors for poor treatment response. ${ }^{133}$ The reason for the poor treatment response in women may be related to the higher incidences of anxiety, depression, or stronger psychological symptoms in women, which are also risk factors for poor treatment response in patients with IBS. ${ }^{134,135}$ Further understanding these mechanisms could help to improve treatment effectiveness.

Probiotics could be an effective treatment for IBS in terms of symptom improvement. A systematic review analyzing 18 randomized controlled trials including 1650 patients with IBS found that probiotics were statistically significantly better than placebo with a number needed to treat of $4 .{ }^{135}$ Probiotics has been reported to have an anti-nociceptive effect on stress-induced visceral hypersensitivity in animal models, and they are known to increase the expression of opioid and cannabinoid receptors in intestinal epithelial cells. ${ }^{136}$ Probiotics have also been reported to inhibit micro-inflammation of the intestine. ${ }^{137}$ However, the therapeutic effect of probiotics in IBS depends on the strains of probiotics used and the different mixtures and dosages of these strains. ${ }^{137}$ In addition, differences in the numbers of men and women participating in the study may have an im- pact on the effectiveness of probiotics treatments because of differences in the courses of IBS in men and women. Gender differences may also influence the response to probiotics in IBS treatment, but these differences have not yet been fully explored. ${ }^{137}$

A recent study by Lee et $\mathrm{al}^{61}$ investigated the effect of probiotics in the repeated water avoidance stress (rWAS)-induced colonic microinflammation model of Wistar rats in a sex-specific manner. Chronic psychological stress (rWAS) was found to significantly increase bowel frequency, and induce visceral analgesia in female rats, but not in males. ${ }^{4,61}$ In addition, the number of mast cells in the distal colon was significantly higher in female rats of the WAS group, and the modulation effect of probiotics was greater in female rats than in male rats. ${ }^{61}$ Similarly, rWAS induced the mRNA expression of various colonic mucosal cytokines, and probiotics therapy decreased these only in female rats, suggesting that there is a sexrelated difference in the micro-inflammation of the colon. ${ }^{61}$ These results can help to understand the role of probiotics in IBS and suggest the possibility of using mast cells and cytokines as treatment targets in women with IBS. ${ }^{61}$

\section{Diet}

Patients have suggested that diet has a role in the pathogenesis of the syndrome itself and also as a trigger of symptoms. ${ }^{138}$ Twothirds of IBS patients believe that their complaints are related to food. ${ }^{139}$ Putative food intolerances are reported by $20-70 \%$ of patients with IBS, although true allergies are rare. ${ }^{140}$ Therefore, dietary management is recommended as an important part of the treatment of IBS. ${ }^{141-143}$

In a study conducted to investigate food groups and specific food items that cause GI symptoms in IBS patients, women tended to report more food items that cause symptoms than men. ${ }^{144}$ Increased fiber and fish intake, decreased fatty meal intake, reduced sweets, red meat, and reduced coffee and alcohol intake were all significantly different between the case and control groups of women. The male IBS group showed only significantly lower bread intake than the male control group. As the number of foods reported to cause GI symptoms increased, the $\mathrm{QoL}$ of the patients were decreased, which was also related to energy, food, sleep, social role, and physical condition. ${ }^{144}$ In addition, female IBS patients were more willing to change their dietary habits due to GI trouble than men. The majority of women and men who changed their dietary habits due to GI trouble reported improvement of their symptoms. ${ }^{144} \mathrm{~A}$ large cross-sectional French cohort study evaluating the association between vegetarian diet and IBS reported a higher prevalence of IBS in women than in men $(5.6 \%$ vs $4.8 \% ; P=0.03) .{ }^{116}$ Stable 
vegetarian diets (ie, self-declared at least 3 times) were related with IBS, IBS-M, and IBS-D, suggesting that long-term vegetarian diet might be related to IBS as well. In that study, vegetarians consumed more simple carbohydrates and complex carbohydrates than non-vegetarians. ${ }^{116}$

Increases in certain types of carbohydrates in one's diet can worsen IBS symptoms, particularly of sugars (monosaccharides and disaccharides) and polyols, which are slowly absorbed in the small intestine rather than digested, and can induce luminal expansion through a variety of mechanisms. ${ }^{141}$ A recent systematic review of 9 randomized trials reported a short-term benefit of low fermentable oligosaccharides, disaccharides, monosaccharides, and polyols (FODMAPs) diet for IBS patients considering GI symptoms, abdominal pain, and QoL improvement, while adverse effects were not reported. ${ }^{119}$ With regard to the participants, between $67.0 \%$ and $86.0 \%$ (median: $71.0 \%$ ) of subjects in each study were women. ${ }^{144}$ Another meta-analysis comparing the treatment effect of a low FODMAP diet for IBS symptoms and QoL to that of a regular, standard IBS diet with high FODMAP demonstrated that the low FODMAP diets were associated with overall improvement of IBS symptoms. ${ }^{145}$ However, the long-term outcomes and safety of low FODMAP diets remain to be investigated. ${ }^{145}$ Sex difference in the benefits of low FODMAP diet have not yet been analyzed either. Larger multicenter trials are needed to better elucidate the mechanisms involved and to identify the subsets of patients who are more likely to respond to this relatively complex dietary intervention by considering gender issues. ${ }^{119,145}$

\section{Conclusions}

To date, several studies have demonstrated that there are sexand gender-differences in the prevalence, pathophysiology, symptoms, gender role, and treatment response of IBS. For one, IBS occurs more often in women than in men. However, the reasons for why IBS is predominant in women remain to be explored in detail. With regard to symptoms, women more often complain of abdominal pain and constipation-related symptoms, while men more commonly report diarrhea-related symptoms. Despite limited comprehensive data, sex hormones are believed to contribute to these gender differences as well as cultural factors and gender roles. Many studies have indicated that sex hormones affect the regulatory mechanisms of the gut-brain axis, stress response, visceral sensitivity and motility, intestinal barrier function, immune activation of intestinal mucosa, and gut microbiota. Women with IBS tend to report lower QoL, more fatigue, depressed mood, less positive well-being and self-control, and higher levels of anxiety than men with IBS. Although relatively few men have participated in clinical trials in pharmacologic treatment, there have been several points of evidence indicating sex differences in the treatment response. Understanding these gender differences in the medical care environment and applying them to IBS patients is important because it can provide better clinical outcomes. Individualized and multicomponent approaches considering sex and gender issues are also necessary for the improved treatment of IBS.

Financial support: This research was supported by Support Program for Women in Science, Engineering and Technology through the National Research Foundation of Korea (NRF) funded by the Ministry of Science and ICT (No. 2016H1C3A1903202).

\section{Conflicts of interest: None.}

Author contributions: Young Sun Kim: design for contents and drafting the article; and Nayoung Kim: key concept and revision.

\section{References}

1. Longstreth GF, Thompson WG, Chey WD, Houghton LA, Mearin F, Spiller RC. Functional Bowel Disorders. Gastroenterology 2006;130:1480-1491.

2. Houghton LA, Heitkemper M, Crowell M, et al. Age, gender and women's health and the patient. Gastroenterology 2016;150:1332-1343, e4.

3. Wizemann TM, Pardue ML. Exploring the biological contributions to human health: does sex matter? Washington, DC: National Academies Press; 2001.

4. Kim YS, Kim N, Kim GH. Sex and gender differences in gastroesophageal reflux disease. J Neurogastroenterol Motil 2016;22:575-588.

5. Kilminster S, Downes J, Gough B, Murdoch-Eaton D, Roberts T. Women in medicine-is there a problem? A literature review of the changing gender composition, structures and occupational cultures in medicine. Medical Educ 2007;41:39-49.

6. Annandale E, Hammarström A. Constructing the 'gender-specific body': a critical discourse analysis of publications in the field of genderspecific medicine. Health 2011;15:571-587.

7. Ahlawat SK, Cuddihy MT, Locke GR 3rd. Gender-related differences in dyspepsia: a qualitative systematic review. Gender Med 2006;3:31-42.

8. Flier SN, Rose S. Is functional dyspepsia of particular concern in women? A review of gender differences in epidemiology, pathophysiologic mechanisms, clinical presentation, and management. Am J Gastroenterol 2006;101(12 suppl):S644-S653.

9. Welén K, Faresjö A, Faresjö T. Functional dyspepsia affects women more than men in daily life: a case-control study in primary care. Gender Med 2008;5:62-73. 
10. Boeckxstaens GE, Drug V, Dumitrascu D, et al. Phenotyping of subjects for large scale studies on patients with IBS. Neurogastroenterol Motil 2016;28:1134-1147.

11. Talley NJ. Irritable bowel syndrome: definition, diagnosis and epidemiology. Baillieres Best Pract Res Clin Gastroenterol 1999;13:371-384.

12. Chial HJ, Camilleri M. Gender differences in irritable bowel syndrome. J Gend Specif Med 2002;5:37-45.

13. Lovell RM, Ford AC. Effect of gender on prevalence of irritable bowel syndrome in the community: systematic review and meta-analysis. Am J Gastroenterol 2012;107:991-1000.

14. Song KH, Jung HK, Kim HJ, et al. Clinical practice guidelines for irritable bowel syndrome in Korea, 2017 revised edition. J Neurogastroenterol Motil 2018;24:197-215.

15. Chang L, Heitkemper MM. Gender differences in irritable bowel syndrome. Gastroenterology 2002;123:1686-1701.

16. Adeyemo MA, Spiegel BM, Chang L. Meta-analysis: do irritable bowel syndrome symtomes vary between men and wome? Aliment Pharmacol Ther 2010;32:738-755.

17. Drossman DA, Camilleri M, Mayer EA, Whitehead WE. AGA technical review on irritable bowel syndrome. Gastroenterology 2002;123:2108-2131.

18. Müller-Lissner SA, Bollani S, Brummer RJ, et al. Epidemiological aspects of irritable bowel syndrome in Europe and North America. Digestion 2001;64:200-204.

19. Sperber AD, Dumitrascu D, Fukudo S, et al. The global prevalence of IBS in adults remains elusive due to the heterogeneity of studies: a rome foundation working team literature reviw. Gut 2017;66:1075-1085.

20. Ghoshal UC, Abraham P, Bhatt C, et al. Epidemiological and clinical profile of irritable bowel syndrome in India: report of the India society of gastroenterology task force. Indian J Gastroenterol 2008;27:22-28.

21. Lee OY. Asian motility studies in irritable bowel syndrome. J Neurogastroenterol Motil 2010;16:120-130.

22. Toner BB, Akman D. Gender role and irritable bowel syndrome: literature review and hypothesis. Am J Gastroenterol 2000;95:11-16.

23. Jung HK. Epidemiology of gastroesophageal reflux disease in Asia: a systematic review. J Neurogastroenterol Motil 2011;17:14-27.

24. Klem F, Wadhwa A, Prokop LJ, et al. Prevalence, risk factors, and outcomes of irritable bowel syndrome after infectious enteritis: a systematic review and meta-analysis. Gastroenterology 2017;152:1042-1054.e1.

25. Mulak A, Taché Y. Sex difference in irritable bowel syndrome: do gonadal hormones play a role? Gastroenterol Pol 2010;17:89-97.

26. García Rodríguez LA, Ruigómez A, Wallander MA, Johansson S, Olbe L. Defection of colorectal tumor and inflammatory bowel disease during follow-up of patients with initial diagnosis of irritable bowel syndrome. Scand J Gastroenterol 2000;35:306-311.

27. Heitkemper MM, Chang L. Do fluctuations in ovarian hormones affect gastrointestinal symptoms in women with irritable bowel syndrome? Gend Med 2009;6(suppl 2):152-167.

28. Longstreth GF, Thompson WG, Chey WD, Houghton LA, Mearin F, Spiller RC. Functional bowel disorders. Gastroenterology 2006;130:1480-1491.

29. Mulak A, Waszczuk E, Paradowski L. Irritable bowel syndrome as an interdisciplinary clinical problem. Adv Clin Exp Med 2008;17:667-675.

30. Warnock JK, Clayton AH. Chronic episodic disorders in women. Psychiatr Clin North Am 2003;26:725-740.

31. Chang L, Toner BB, Fukudo S, et al. Gender, age, society, culture, and the patient's perspective in the functional gastrointestinal disorders. Gastroenterology 2006;130:1435-1446.

32. Georgescu D, Reisz D, Gurban CV, et al. Migraine in young females with irritable bowel syndrome: still a challenge. Neuropsychiatr Dis Treat 2017;14:21-28.

33. Olafsdottir LB, Gudjonsson H, Jonsdottir HH, Björnsson E, Thjodleifsson B. Natural history of irritable bowel syndrome in women and dysmenorrhea: a 10-year follow-up study. Gastroenterol Res Pract 2012;2012:534204.

34. Choghakhori R, Abbasnezhad A, Amani R, Alipour M. Sex-related differences in clinical symptoms, quality of life, and biochemical factors in irritable bowel syndrome. Dig Dis Sci 2017;62:1550-1560.

35. Heitkemper MM, Cain KC, Jarrett ME, Burr RL, Hertig V, Bond EF. Symptoms across the menstrual cycle in women with irritable bowel syndrome. Am J Gastroenterol 2003;98:420-430.

36. Ruigómez A, García Rodríguez LA, Johansson S, Wallander MA. Is hormone replacement therapy associated with an increased risk of irritable bowel syndrome? Maturitas 2003;44:133-140.

37. Gonenne J, Esfandyari T, Camilleri M, et al. Effect of female sex hormone supplementation and withdrawal on gastrointestinal and colonic transit in postmenopausal women. Neurogastroenterol Motil 2006;18:911-918.

38. Chandar AK. Diagnosis and treatment of irritable bowel syndrome with predominant constipation in the primary-care setting: focus on linaclotide. Int J Gen Med 2017;10:385-393.

39. Harris LA, Umar SB, Baffy N, Heitkemper MM. Irritable bowel syndrome and female patients. Gastroenterol Clin North Am 2016;45:179204.

40. Drossman DA. Functional Gastrointestinal disorder: history, pathophysiology, and Rome IV. Gastroenterology 2016;150:1262-1279.

41. Farhadi A, Banton D, Keefer L. Connecting our gut feeling and how our gut feels: the role of well-being attributes in irritable bowel syndrome. J Neurogastroenterol Motil 2018;24:289-298.

42. Meerveld BG, Johnson AC. Mechanisms of stress-induced visceral pain. J Neurogastroenterol Motil 2018;24:7-18.

43. Lee HF, Liu PY, Wang YP, Tsai CF, Chang FY, Lu CL. Sexual abuse is associated withan abnormal psychological profile and sleep difficulty in patients with irritable bowel syndrome in Taiwan. J Neurogastroenterol Motil 2018;24:79-86.

44. Choi YJ, Kim N, Yoon H, et al. Overlap between irritable bowel syndrome and functional dyspepsia including subtype analyses. J Gastroenterol Hepatol 2017;32:1553-1561.

45. Lampe JW, Fredstrom SB, Slavin JL, Potter JD. Sex differences in colonic function: a randomised trial. Gut 1993;34:531-536.

46. Meleine M, Matricon J. Gender-related differences in irritable bowel syndrome: potential mechanisms of sex hormones. World J Gastroenterol 2014;20:6725-6743.

47. Aloisi AM. Gonadal hormones and sex differences in pain reactivity. 
Clin J Pain 2003;19:168-174.

48. Cairns BE, Gazerani P. Sex-related differences in pain. Maturitas 2009;63:292-296.

49. Houghton LA, Jackson NA, Whorwell PJ, Morris J. Do male sex hormones protect from irritable bowel syndrome? Am J Gastroenterol 2000;95:2296-2300.

50. Kim BJ, Rhee PL, Park JH, et al. Male sex hormones may influence the symptoms of irritable bowel syndrome in young men. Digestion 2008;78:88-92.

51. Miller V, Whitaker K, Morris JA, Whorwell PJ. Gender and irritable bowel syndrome: the male connection. J Clin Gastroenterol 2004;38:558-560.

52. Aloisi AM, Bachiocco V, Costantino A, et al. Cross-sex hormone administration changes pain in transsexual women and men. Pain 2007;132:S60-S67.

53. Chang L, Mayer EA, Labus JS, et al. Effect of sex on perception of rectosigmoid stimuli in irritable bowel syndrome. Am J Physiol Regul Integr Comp Physiol 2006;291:R277-R284.

54. Ragnarsson G, Hallböök O, Bodemar G. Abdominal symptoms are not related to anorectal function in the irritable bowel syndrome. Scand J Gastroenterol 1999;34:250-258.

55. Naliboff BD, Berman S, Chang L, et al. Sex-related differences in IBS patients: central processing of visceral stimuli. Gastroenterology 2003;124:1738-1747.

56. Chang L, Adeyemo M, Karagiannides I, et al. Serum and colonic mucosal immune markers in irritable bowel syndrome. Am J Gastroenterol 2012;107:262-272.

57. Martin-Viñas JJ, Quigley EM. Immune response in irritable bowel syndrome: a systematic review of systemic and mucosal inflammatory mediators. J Dig Dis 2016;17:572-581.

58. Cremon C, Gargano L, Morselli-Labate AM, et al. Mucosal immune activation in irritable bowel syndrome: gender-dependence and association with digestive symptoms. Am J Gastroenterol 2009;104:392-400.

59. Bashashati M, Rezaei N, Shafieyoun A, et al. Cytokine imbalance in irritable bowel syndrome: a systematic review and meta-analysis. Neurogastroenterol Motil 2014;26:1036-1048.

60. Pigrau M, Rodiño-Janeiro BK, Casado-Bedmar M, et al. The joint power of sex and stress to modulate brain-gut microbiota axis and intestinal barrierhomeostasis: implications for irritable bowel syndrome. Neurogastroenterol Motil 2016;28:463-486.

61. Lee JY, Kim N, Kim YS, et al. Repeated water avoidance stress alters mucosal mast cell counts, interleukin-1 $\beta$ levels with sex difference in distal colon of wistar rats. J Neurogastroenterol Motil 2016;22:694-704.

62. Mulak A, Taché Y, Larauche M. Sex hormones in the modulation of irritable bowel syndrome. World J Gastroenterol 2014;20:2433-2448.

63. Zheng G, Wu SP, Hu Y, Smith DE, Wiley JW, Hong S. Corticosterone mediates stress-related increased intestinal permeability in a regionspecific manner. Neurogastroenterol Motil 2013;25:e127-e139.

64. Honda J, Iijima K, Asanuma K, et al. Estrogen enhances esophageal barrier function by potentiating occludin expression. Dig Dis Sci 2016;61:1028-1038.

65. Cotter AA, Cashman KD. Effect of 17beta-oestradiol on transepithelial calcium transport in human intestinal-like Caco-2 cells and its interactions with 1,25-dihydroxycholecalciferol and 9-cis retinoic acid. Eur J Nutr 2006;45:234-241.

66. Braniste V, Leveque M, Buisson-Brenac C, Bueno L, Fioramonti J, Houdeau E. Oestradiol decreases colonic permeability through oestrogen receptor beta-mediated up-regulation of occludin and junctional adhesion molecule-A in epithelial cells. J Physiol 2009;587(Pt 13):33173328.

67. Braniste V, Jouault A, Gaultier E, et al. Impact of oral bisphenol A at reference doses on intestinal barrier function and sex differences after perinatal exposure in rats. Proc Natl Acad Sci USA 2010;107:448-453.

68. Moussa L, Bézirard V, Salvador-Cartier C, Bacquié V, Houdeau E, Théodorou $\mathrm{V}$. A new soy germ fermented ingredient displays estrogenic and protease inhibitor activities able to prevent irritable bowel syndromelike symptoms in stressed female rats. Clin Nutr 2013;32:51-58.

69. Distrutti E, Monaldi L, Ricci P, Fiorucci S. Gut microbiota role in irritable bowel syndrome: new therapeutic strategies. World J Gastroenterol 2016;22:2219-2241.

70. Ait-Belgnaoui A, Payard I, Rolland C, et al. Bifidobacterium longum and Lactobacillus helveticus synergistically suppress stress-related visceral hypersensitivity through hypothalamic-pituitary-adrenal axis modulation. J Neurogastroenterol Motil 2018;24:138-146.

71. Menon R, Watson SE, Thomas LN, et al. Diet complexity and estrogen receptor $\beta$ status affect the composition of the murine intestinal microbiota. Appl Environ Microbiol 2013;79:5763-5773.

72. Markle JG, Frank DN, Mortin-Toth S, et al. Sex differences in the gut microbiome drive hormone dependent regulation of autoimmunity. Science 2013;339:1084-1088.

73. Mattar AF, Teitelbaum DH, Drongowski RA, Yongyi F, Harmon CM, Coran AG. Probiotics up-regulate MUC-2 mucin gene expression in a Caco-2 cell-culture model. Pediatr Surg Int 2002;18:586-590.

74. Kim Y, Kim SH, Whang KY, Kim YJ, Oh S. Inhibition of Escherichia coli O157: $\mathrm{H} 7$ attachment by interactions between lactic acid bacteria and intestinal epithelial cells. J Microbiol Biotechnol 2008;18:12781285.

75. Da Silva S, Robbe-Masselot C, Ait-Belgnaoui A, et al. Stress disrupts intestinal mucus barrier in rats via mucin $O$-glycosylation shift: prevention by a probiotic treatment. Am J Physiol Gastrointest Liver Physiol 2014;307:G420-G429.

76. Shastri P, McCarville J, Kalmokoff M, Brooks SP, Green-Johnson JM. Sex differences in gut fermentation and immune parameters in rats fed an oligofructose-supplemented diet. Biol Sex Differ 2015;6:13.

77. Tremaroli V, Bäckhed F. Functional interactions between the gut microbiota and host metabolism. Nature 2012;489:242-249.

78. Kim SY, Choung RS, Lee SK, et al. Self reported sleep impairment in functional dyspepsia and irritable bowel syndrome. J Neurogastroenterol Motil 2018;24:280-288.

79. Simrén M, Abrahamsson H, Svedlund J, Björnsson ES. Quality of life in patients with irritable bowel syndrome seen in referral centers versus primary care: the impact of gender and predominant bowel pattern. Scand J Gastroenterol 2001;36:545-552.

80. Choi YJ, Park YS, Kim N, et al. Gender differences in ghrelin, nocicep- 
tion genes, psychological factors and quality of life in functional dyspepsia. World J Gastroenterol 2017;23:8053-8061.

81. Park JM, Choi MG, Kim YS, et al. Quality of life of patients with irritable bowel syndrome in Korea. Qual Life Res 2009;18:435-446.

82. Corney RH, Stanton R. Physical symptom severity, psychological and social dysfunction in a series of outpatients with irritable bowel syndrome. J Psychosom Res 1990;34:483-491.

83. Faresjö A, Grodzinsky E, Johansson S, Wallander MA, Timpka T, Akerlind I. A population-based case-control study of work and psychosocial problems in patients with irritable bowel syndrome-women are more seriously affected than men. Am J Gastroenterol 2007;102:371-379.

84. Halder SL, Locke GR 3rd, Talley NJ, Fett SL, Zinsmeister AR, Melton LJ 3rd. Impact of functional gastrointestinal disorders on healthrelated quality of life: a population-based case-control study. Aliment Pharmacol Ther 2004;19:233-242.

85. Michalsen VL, Vandvik PO, Farup PG. Predictors of health-related quality of life in patients with irritable bowel syndrome. A cross-sectional study in Norway. Health Qual Life Outcomes 2015;13:113.

86. Hulme K, Chilcot J, Smith MA. Doctor-patient relationship and quality of life in irritable bowel syndrome: an exploratory study of the potential mediating role of illness perceptions and acceptance. Psychol Health Med 2018;23:674-684.

87. Frissora CL, Koch KL. The role of gender and biological sex in irritable bowel syndrome. Curr Gastroenterol Rep 2005;7:257-263.

88. Cheney AM. "Most girls want to be skinny": body (dis)satisfaction among ethnically diverse women. Qual Health Res 2011;21:1347-1359.

89. Payne S. Sex, gender, and irritable bowel syndrome: making the connections. Gend Med 2004;1:18-28.

90. Ali A, Toner BB, Stuckless N, et al. Emotional abuse, self-blame and self-silencing in women with irritable bowel syndrome. Psychosom Med 2000;62:76-82.

91. Björkman I, Dellenborg L, Ringström G, Simrén M, Jakobsson Ung E. The gendered impact of irritable bowel syndrome: a qualitative study of patients' experiences. J Adv Nurs 2014;70:1334-1343.

92. Pimentel M, Lembo A, Chey WD, et al.. Rifaximin therapy for patients with irritable bowel syndrome without constipation. N Engl J Med 2011;364:22-32.

93. El-Serag HB. Impact of irritable bowel syndrome: prevalence and effect on health-related quality of life. Rev Gastroenterol Disord 2003;3(suppl 2):S3-S11.

94. Gibson PR,Varney J, Malakar S, Muir JG. Food components and irritable bowel syndrome. Gastroenterology 2015;148:1158-1174, e4 .

95. O’Mahony L, McCarthy J, Kelly P, et al. Lactobacillus and bifidobacterium in irritable bowel syndrome: symptom responses and relationship to cytokine profiles. Gastroenterology 2005;128:541-551.

96. Ouyang A, Wrzos HF. Contribution of gender to pathophysiology and clinical presentation of IBS: should management be different in women? Am J Gastroenterol 2006;101(12 suppl):S602-S609.

97. Lunsford TN, Harris LA. Lubiprostone: evaluation of the newest medication for the treatment of adult women with constipation-predominant irritable bowel syndrome. Int J Womens Health 2010;2:361-374.

98. Camilleri M, Mayer EA, Drossman DA, et al. Improvement in pain and bowel function in female irritable bowel patients with alosetron, a 5-HT 3 receptor antagonist. Aliment Pharmacol Ther 1999;13:11491159

99. Camilleri M, Northcutt AR, Kong S, Dukes GE, McSorley D, Mangel AW. Efficacy and safety of alosetron in women with irritable bowel syndrome: a randomised, placebo-controlled trial. Lancet 2000;355:10351040 .

100. Katsumata R, Shiotani A, Murao T, et al. Gender differences in serotonin signaling in patients with diarrhea-predominant irritable bowel syndrome. Intern Med 2017;56:993-999.

101. Scott LJ, Perry CM. Tegaserod. Drugs 1999;58:491-496; discussion 497-498.

102. Chang L, Ameen VZ, Dukes GE, McSorley DJ, Carter EG, Mayer EA. A dose-ranging, phase II study of the efficacy and safety of alosetron in men with diarrhea-predominant IBS. Am J Gastroenterol 2005;100:115-123.

103. Ford AC, Brandt LJ, Young C, Chey WD, Foxx-Orenstein AE, Moayyedi P. Efficacy of 5- $\mathrm{HT}_{3}$ antagonists and $5-\mathrm{HT}_{4}$ agonists in irritable bowel syndrome: systematic review and meta-analysis. Am J Gastroenterol 2009;104:1831-1843.

104. Zheng Y, Yu T, Tang Y, et al. Efficacy and safety of 5-hydroxytryptamine 3 receptor antagonists in irritable bowel syndrome: a systematic review and meta-analysis of randomized controlled trials. PLoS One 2017;12:e0172846.

105. Ringel Y, Carroll IM. Alterations in the intestinal microbiota and functional bowel symptoms. Gastrointest Endosc Clin N Am 2009;19:141150 , vii.

106. Camilleri M, Atanasova E, Carlson PJ, et al. Serotonin-transporter polymorphism pharmacogenetics in diarrhea-predominant irritable bowel syndrome. Gastroenterology 2002;123:425-432.

107. Garsed K, Chernova J, Hastings M, et al. A randomised trial of ondansetron for the treatment of irritable bowel syndrome with diarrhoea. Gut 2014;63:1617-1625.

108. Lee KJ, Kim NY, Kwon JK, et al. Efficacy of ramosetron in the treatment of male patients with irritable bowel syndrome with diarrhea: a multicenter, randomized clinical trial, compared with mebeverine. Neurogastroenterol Motil 2011;23:1098-1104.

109. Fukudo S, Ida M, Akiho H, Nakashima Y, Matsueda K. Effect of ramosetron on stool consistency in male patients with irritable bowel syndrome with diarrhea. Clin Gastroenterol Hepatol 2014;12:953-959.e4.

110. Fukudo S, Kinoshita Y, Okumura T, et al. Ramosetron reduces symptoms of irritable bowel syndrome with diarrhea and improves quality of life in women. Gastroenterology 2016;150:358-366.e8.

111. Lembo A, Pimentel M, Rao SS, et al. Repeat treatment with rifaximin is safe and effective in patients with diarrhea-predominant irritable bowel syndrome. Gastroenterology 2016;151:1113-1121.

112. Ford AC, Quigley EM, Lacy BE, et al. Effect of antidepressants and psychological therapies, including hypnotherapy, in irritable bowel syndrome: systematic review and meta-analysis. Am J Gastroenterol 2014;109:1350-1365.

113. Lee HH, Choi YY, Choi MG. The Efficacy of hypnotherapy in the treatment of irritable bowel syndrome: a systematic reviewand meta- 
analysis. J Neurogastroenterol Motil 2014;20:152-162.

114. Ustün TB. Cross-national epidemiology of depression and gender. J Gend Specif Med 2000;3:54-58.

115. Johanson JF, Ueno R. Lubiprostone, a locally acting chloride channel activator, in adult patients with chronic constipation: a double-blind, placebo-controlled, dose-ranging study to evaluate efficacy and safety. Aliment Pharmacol Ther 2007;25:1351-1361.

116. Buscail C, Sabate JM, Bouchoucha M, et al. Association between selfreported vegetarian diet and the irritable bowel syndrome in the FrenchNutriNet cohort. PLoS One 2017;12:e0183039.

117. Lembo AJ, Schneier HA, Shiff SJ, et al. Two randomized trials of linaclotide for chronic constipation. N Engl J Med 2011;365:527-536.

118. Barshop K, Staller K. Eluxadoline in irritable bowel syndrome with diarrhea: rationale, evidence and place in therapy. Ther Adv Chronic Dis 2017;8:153-160.

119. Schumann D, Klose P, Lauche R, Dobos G, Langhorst J, Cramer H. Low fermentable, oligo-, di-, mono-saccharides and polyol diet in the treatment of irritable bowel syndrome: a systematic review and metaanalysis. Nutrition 2018;45:24-31.

120. Johanson JF, Morton D, Geenen J, Ueno R. Multicenter, 4-week, double-blind, randomized, placebo-controlled trial of lubiprostone, a locally-acting type-2 chloride channel activator, in patients with chronic constipation. Am J Gastroenterol 2008;103:170-177.

121. Fukudo S, Kinoshita Y, Okumura T, et al. Effect of ramosetron in female patients with irritable bowel syndrome with diarrhea: a phase III longterm study. J Gastroenterol 2016;51:874-882.

122. Qi Q, Zhang Y, Chen F, Zuo X, Li Y. Ramosetron for the treatment of irritable bowel syndrome with diarrhea: a systematic review and metaanalysis of randomized controlled trials. BMC Gastroenterol 2018;18:5.

123. Heils A, Teufel A, Petri S, et al. Allelic variation of human serotonin transporter gene expression. J Neurochem 1996;66:2621-2624.

124. Choi YJ, Hwang SW, Kim N, Park JH, Oh JC, Lee DH. Association between SLC6A4 serotonin transporter gene linked polymorphic region and ADRA2A $1291 \mathrm{C}>\mathrm{G}$ and irritable bowel syndrome in Korea. J Neurogastroenterol Motil 2014;20:388-399.

125. Chey WD, Lembo AJ, Lavins BJ, et al. Linaclotide for irritable bowel syndrome with constipation: a 26-week, randomized, double-blind, placebo-controlled trial to evaluate efficacy and safety. Am J Gastroenterol 2012;107:1702-1712.

126. Lembo AJ, Lacy BE, Zuckerman MJ, et al. Eluxadoline for irritable bowel syndrome with diarrhea. N Engl J Med 2016;374:242-253.

127. Ford AC, Talley NJ, Spiegel BM, et al. Effect of fibre, antispasmodics, and peppermint oil in the treatment of irritable bowel syndrome: systematic review and meta-analysis. BMJ 2008;337:a2313.

128. Anderson GD. Sex and racial differences in pharmacological response: where is the evidence? Pharmacogenetics, pharmacokinetics, and pharmacodynamics. J Womens Health (Larchmt) 2005;14:19-29.

129. Tran C, Knowles SR, Liu BA, Shear NH. Gender differences in ad- verse drug reactions. J Clin Pharmacol 1998;38:1003-1009.

130. Kaiser J. Gender in the pharmacy: does it matter? Science 2005;308: 1572.

131. Rademaker M. Do women have more adverse drug reactions? Am J Clin Dermatol 2001;2:349-351.

132. Meibohm B, Beierle I. Derendorf H. How important are gender differences in pharmacokinetics? Clin Pharmacokinet 2002;41:329-342.

133. Yamada E, Tsunoda S, Abe T, et al. Factors associated with poor therapeutic response in outpatients with irritable bowel syndrome: a multicenter study in Japan. J Gastroenterol 2017;52:301-307.

134. Creed F. The relationship between psychosocial parameters and outcome in irritable bowel syndrome. Am J Med 1999;107(5A):74S-80S.

135. Moayyedi P, Ford AC, Talley NJ, et al. The efficacy of probiotics in the treatment of irritable bowel syndrome: a systematic review. Gut 2010;59:325-332.

136. Dai C, Zheng CQ, Jiang M, Ma XY, Jiang LJ. Probiotics and irritable bowel syndrome. World J Gastroenterol 2013;19:5973-5980.

137. Lee BJ, Bak YT. Irritable bowel syndrome, gut microbiota and probiotics. J Neurogastroenterol Motil 2011;17:252-266.

138. Zahedi MJ, Behrouz V, Azimi M. Low fermentable oligo-di-monosaccharides and polyols diet versus general dietary advice in patients with diarrhea-predominant irritable bowel syndrome: a randomized controlled trial. J Gastroenterol Hepatol 2018;33:1192-1199.

139. Lacy BE, Weiser K, Noddin L, et al. Irritable bowel syndrome: patients' attitudes, concerns and level of knowledge. Aliment Pharmacol Ther 2007;25:1329-1341.

140. Cuomo R, Andreozzi P, Zito FP, Passananti V, De Carlo G, Sarnelli G. Irritable bowel syndrome and food interaction. World J Gastroenterol 2014;20:8837-8845.

141. Böhn L, Störsrud S, Liljebo T, et al. Diet low in FODMAPs reduces symptoms of irritable bowel syndrome as well as traditional dietary advice: a randomized controlled trial. Gastroenterology 2015;149:13991407.e2.

142. Jung KW, Seo M, Cho YH. et al. Prevalence of fructose malabsorption in patients with irritable syndrome after excluding small intestinal bacterial overgrowth. J Neurogastroenterol Motil 2018;24:307-316.

143. Kim Y, Choi CH. Role of fructose malabsorption in patients with irritable bowel syndrome. J Neurogastroenterol Motil 2018;24:161-163.

144. Böhn L, Störsrud S, Törnblom H, Bengtsson U, Simrén M. Selfreported food-related gastrointestinal symptoms in IBS are common and associated with more severe symptoms and reduced quality of life. Am J Gastroenterol 2013;108:634-641.

145. Varjú P, Farkas N, Hegyi P, et al. Low fermentable oligosaccharides, disaccharides, monosaccharides and polyols (FODMAP) diet improves symptoms in adults suffering from irritable bowel syndrome (IBS) compared to standard IBS diet: a meta-analysis of clinical studies. PLoS One 2017;12:e0182942. 